\title{
COMMENTARY
}

\section{Community: The Heart of Family Medicine}

Santina Wheat, MD, MPH

(Fam Med. 2021;53(7):528-30.)

doi: 10.22454/FamMed.2021.503235

Published Online First June 11, 2021

ABSTRACT: Family physicians have the privilege of caring for patients throughout their lifespan and witness the impact all facets of life have on the health of individuals and the health of communities. The importance of engaging the community in the success of population-based initiatives to drive social change has been proven repeatedly and family medicine residencies should include community as the fifth "C." At a minimum, this includes incorporating the following three recommendations: (1) define community on initial accreditation, at self-study, and whenever major community changes occur; (2) utilize a community needs assessment as part of goal setting of activities with Annual Action Plan; and (3) evaluate residents and faculty on understanding of and cooperation with community needs. We must highlight engagement with the community as a central aspect of family medicine so that all programs focus on this important aspect of our work.

A s a nation, we have unfortunately seen decreasing life expectancy since 2014 along with increasing clarity that our health outcomes are poor. We also acknowledge disparities in education, housing, economic opportunity, and access to justice. ${ }^{1,2}$ Although not strictly health care, these disparities impact patients' health and we cannot see improvement in health without understanding their significance. A nearly 20-year gap exists in life expectancy at birth amongst counties with the highest and lowest life expectancy rates. ${ }^{3} \mathrm{We}$ family physicians have the privilege of caring for patients throughout their lifespan and witness the impact all facets of life have on the health of individuals and the health of communities. We must take action to improve health for all. The American Board of Family Medicine shared the premise "that the personal physician should play a critical role in rebuilding a health system that can address the Triple Aim." Additionally, a survey of American Academy of Family Physicians indicated that family physicians want to address the sociallydetermined health needs of our patients, but face barriers in doing so. ${ }^{1}$ Family physicians want to do this work. How do we train them to be successful?
Across disciplines, the importance of engaging the community in the success of population-based initiatives to drive social change has been proven repeatedly. When initiatives are conducted without community collaboration, they are perceived in a top-down manner and are more likely to fail. Israel et al and Minkler et al demonstrated nine principles of community-based participatory research. Additionally, Barnes and Schmitz recommend certain factors exist for community engagement to achieve positive and enduring social change. These principles focus on the definition of the community, methods of collaboration, engagement and education, use of relevance, use of iterative processes, dissemination of results, sustainability, cultural humility, and validity., Family medicine should participate in these efforts for social change to positively affect health. Therefore, our education must teach residents how to first identify, and then engage the community so residents may collaborate on effective population-based initiatives. Family

From the McGaw Northwestern Family Medicine Residency Program at Humboldt Park, Northwestern University Feinberg School of Medicine, Chicago, IL; and Lending Hands for Life and Erie Family Health Centers, Chicago, IL. 
medicine residency programs should include a fifth "C" for Community as an important tenet of training and should at a minimum follow three overall recommendations as listed in Table 1.

\section{Define a Community}

The term community has many different connotations. Community is complex and most importantly meets the shared needs of a group of people. ${ }^{6}$ Each residency's community will have different needs and will change over time. In some instances, community may be defined by geographic location, particularly in a rural setting. In urban and suburban areas, a community may be defined by location, but also may be defined by specific characteristics such as patients living at less than $200 \%$ of the poverty level within certain zip codes, or immigrant persons living in a specific geographic area. At times, the population and community may overlap, though they are not the same. In medicine, we often discuss population health with panel medicine, but this is not always the community truly served by the residency program. Each residency program must clearly define the community they are serving with the program evaluation committee (PEC) at minimum upon initial accreditation, and as part of their self-study. They should also consider revisiting it every 5 years if the surrounding community has changed. For example, the impact of telehealth has increased the geographic reach for many programs, significantly broadening communities. In some instances, programs may identify more than one community due to more than one continuity location or distance of main hospital, and this should be clearly indicated. Clearly defined communities for each program ensure common understanding and will impact how residencies choose which activities and projects will best fit their needs.

\section{Use Community Needs Assessment to Define Activities}

Once a program defines a community, clear attempts to assess the needs for and ability to participate in the community should be made.
Full initiatives including a needs assessment, community engagement, evaluation, and lasting change are likely not achievable for individual residents within the short time frame of residency education. However, there are a variety of ways in which community engagement can be achieved and measured within a residency program. Community as a requirement must be flexible and allow for innovation. It should allow for different levels of the residency's involvement in the community over time as meaningful relationships evolve over time. Aspects demonstrating involvement with and education about community include education of principles, exposure/engagement, and advocacy. Some opportunities could be longitudinal in nature and some could be brief experiences included in didactics and block rotations. The PEC should take an active role in ensuring the program's incorporation of community, as is demonstrated in Table 2. Utilizing the PEC goals, the program should ensure a variety of activities to focus on the community. Table 3 gives possible activities, though the list is not exhaustive. Although during residency residents will best learn to care for the community they serve, training should include how to engage any community that residents may serve, so that family physicians are flexible throughout their careers as they have career transitions or their surrounding community changes.

\section{Resident and Faculty Evaluation}

Evaluations of each resident can be expanded to include a focus on community in several competencies. Within the Practice-Based Learning and Improvement Milestone, residents are currently assessed on the understanding of how evidence can be tailored to specific patients. This area should be enhanced to assess residents' knowledge of how guidelines and interventions impact different communities. This competency can also be expanded to suggest a goal of a process improvement activity based on a community needs assessment. The Systems-Based Practice competency is another space where a focus on community may be enhanced. Already including advocacy, this Milestone includes aspects of

Table 1: Minimum Recommendations for Community Incorporation

1. Define community served by residency program on initial accreditation, at self-study, and when major community changes.

2. Utilization of community needs assessment as part of goal setting of activities with annual action plan.

3. Evaluate residents and faculty on understanding of and cooperation with community needs. 
Table 2: Program Evaluation Committee's Responsibility Concerning Community

1. Define the residency's community

2. Utilize community needs assessment to identify areas of opportunity for program as part of annual goal setting.

3. Evaluate program's effectiveness at meeting community needs during annual program evaluation.

\section{Table 3: Community Activity Opportunities}

1. Participation in local department of public health meetings:

a. Observation

b. Provide testimony

2. Advocacy with local officials about health needs of community:
a. Meetings with local officials
b. Letters to the editor and op-eds
c. Appropriate engagement with social media

3. Creation of and participation in Patient education groups, activities, social media:

a. Education sessions hosted at community organizations

b. Participation in health fairs

c. Health education group at clinic - in person and/or virtual

4. QI project based on local public health needs Assessment
a. Disparities calculator amongst disease states within clinic or hospital
b. Assessment of social determinants of health needs in clinic or hospital
c. Utilization of geomapping software to identify specific interventions

5. Partnership with community organization for research, intervention, or organized activity:
a. Health screenings
b. Food pantry
c. Care in shelters or other congregated facilities

6. Didactic education:
a. Process of identification of community served
b. Education on community based participatory research principles
c. Education on principles of community engagement
d. Community organizations presenting ongoing projects, resources, and opportuni- ties
e. Journal club evaluation of guidelines with impact on the residency community

Abbreviation: QI, quality improvement.

integration with local, state, and federal health leaders. This could be expanded to include incorporation of community groups and agencies and advocacy on local, state, and federal levels based upon the needs of the community. Program directors also should expand faculty evaluations to assess these same competencies.

In the previous project about the future of family medicine, the definition of family physicians included adaptations to the unique needs of patients and communities. As such, many of the recommendations made are educational opportunities that many programs have already begun to incorporate. We must, however, highlight engagement with the community as a central aspect of family medicine so that all programs focus on this important aspect of our work.

PRESENTATIONS: Content from this article was previously presented at the Re-Envisioning Family Medicine Residency Education Summit.

CORRESPONDENCE: Address correspondence to Dr Santina Wheat, 4443 N Albany, Chicago, IL 60625. 773-2204151. Santina.wheat@northwestern.edu.

\section{References}

1. The EveryONE Project. American Academy of Family Physicians. https://www.aafp.org/family-physician/patient-care/ the-everyone-project.html. Accessed March 10, 2021.

2. Disparities. US Office of Disease Prevention and Health Promotion: HealthyPeople.gov. https://www.healthypeople. gov/2020/about/foundation-health-measures/Disparities. Accessed March 10, 2021.

3. Dwyer-Lindgren L, Bertozzi-Villa A, Stubbs RW, et al. Inequalities in life expectancy among US counties, 1980 to 2014: temporal trends and key drivers. JAMA Intern Med. 2017;177(7):1003-1011. doi:10.1001/jamainternmed.2017.0918

4. Barnes M, Schmitz P. Community engagement matters (Now more than ever). Stanf Soc Innov Rev. 2016.

5. Minkler M, Carcia A, Rubin V, Wallerstein N. Communitybased participatory research: a strategy for building healthy communities and promoting health through policy change. Los Angeles, CA: California Endowment; 2012.

6. Chavis D, Lee K. What is community anyway? Standord Social Innovation Review; May 12, 2015. https://ssir.org/ articles/entry/what_is_community_anyway. Accessed April $23,2021$. 